INKLUSIF Vol 3. No. 2 Desember 2018

\title{
PERAN DEWAN PENGAWAS SYARIAH TERHADAP BMT (BAITUL MAAL TAMWIL) DI PURWOKERTO
}

\author{
Agus Irianto $^{1}$ \\ Email : airianto153@gmail.com
}

\begin{abstract}
$B M T$ Is a very strategic microfinance institution in translating and practicing sharia economic systems in a wide and small community environment. Therefore, assistance to BMT is an activity that needs to be mobilized as part of shariah compliance in sharia financial institutions. $B M T$ in its operations must strictly comply with sharia provisions. Sharia principles must be applied to the contracts used in the sharia-compliant Islamic banks in question are the principles of Islamic law in fact-based banking activities issued by the National Sharia Council of the Indonesian Ulema Council (DSN-MUI). Theparty overseeing the implementation of sharia principles in BMT is the DPS whose role is to oversee and ensure that Islamic banks are operational in accordance with sharia principles. Thus, the role of DPS is very important because to ensure there is no sharia compliance in BMT.
\end{abstract}

Keywords: DPS, BMT, Syariah Compliance

\begin{abstract}
ABSTRAK
BMT Merupakan lembaga keuangan mikro yang sangat strategis dalam menterjemahkan dan mempratekkan sistem ekonomi syariah di lingkungan masyarakat luas dan kecil. Oleh karenanya pendampingan terhadap BMT merupakan kegiatan yang perlu digerakan sebagai bagian dari shariah compliance di lembaga keuangan syariah. BMT dalam operasionalnya harus benar-benar mematuhi ketentuan-ketentuan syariah. Prinsip syariah harus diterapkan pada akad-akad yang digunakan di bank syariah prinsip syariah yang dimaksud adalah prinsip hukum Islam dalam kegiatan perbankan berdasarkan fakta yang dikeluarkan oleh Dewan Syariah Nasional Majelis Ulama Indonesia (DSN-MUI). Pihak yang mengawasi penerapan prinsip syariah di BMT adalah DPS yang berperan untuk mengawal dan memastikan bahwa bank syariah dalam operasionalnya sesuai dengan prinsip syariah. Dengan demikian, peran DPS sangat penting karena untuk memastikan ada tidak adanya kepatuhan syariah di BMT.
\end{abstract}

Kata Kunci: DPS, BMT, Syariah Compliance

${ }^{1}$ Mahasiswa Pascasarjana IAIN Syekh Nurjati Cirebon.

Submitted: August 10, 2018; Reviewed: August 15, 2018, 2018; Accepted: Oktober 16, 
INKLUSIF Vol 3. No. 2 Desember 2018

\section{PENDAHULUAN}

\section{A. Latar Belakang}

Sejatinya BMT sebagai lembaga intermediary dalam jasa keuangan, maka pengawasannya di bawah OJK. Namun lembaga pengawas BMT belum jelas. Dinas Koperasi tidak optimal dalam pengawasan demikian juga OJK. Hal ini terjadi karena terdapat beberapa problem kelembagaan pada BMT secara umum , dan secara khusus BMT yang berada di wilayah kabupaten Purwokerto. ${ }^{2}$ Pertama, secara yuridis, legalitas BMT yang selama ini berjalan dikeluarkan oleh Dinas Koperasi. Sedangkan dari aspek produk yang dikembangkan BMT seperti duplikasi bank syariah. Sehingga esensi kelembagaan di bawah koperasi menjadi biasa, karena SDM yang dimiliki serta operasionalisasinya, BMT seakan-akan adalah bank syariah, bukan turunan dari koperasi. Kondisi ini menjadi sesuatu yang kurang menguntungkan, jika terjadi hal negatif pada lembaga BMT, maka seakan-akan bank syariah yang melakukannya. Kedua, dari aspek likuiditas, control BMT secara monopoli dikendalikan oleh pemilik saham (stack holder), dan manajer. Terjadi ambivalensi operasional dalam kendali likuiditas BMT yang berbeda dengan koperasi. Jika secara konsisten, BMT karena legalitasnya dikeluarkan oleh Dinas Koperasi, maka nasabah BMT merupakan anggota yang berhak mengontrol dan wajib diberitahu tentang arus modal dan likuiditas yang berjalan di BMT melalui Rapat Anggota Tahunan (RAT), bukan sekedar customer dalam transaksi keuangan atau layaknya nasabah bank. Problem ini semakin bertambah, karena telah banyak berkembang lembaga syariah di bawah Dinas Koperasi, yaitu Koperasi Syariah atau Kopontren yang secara konsisten menjalankan dasar-dasar koperasi sesuai prinsip syariah.

BMT dalam operasionalnya harus benar-benar mematuhi ketentuan-ketentuan syariah. Prinsip syariah harus diterapkan pada akad-akad yang digunakan di bank syariah prinsip syariah yang dimaksud adalah prinsip hukum Islam dalam kegiatan perbankan berdasarkan fakta yang dikeluarkan oleh Dewan Syariah Nasional Majelis Ulama Indonesia (DSN-MUI). ${ }^{3}$ Pihak yang mengawasi penerapan prinsip syariah di BMT adalah DPS yang berperan untuk mengawal dan memastikan bahwa bank syariah dalam operasionalnya sesuai dengan prinsip syariah. Dengan demikian, peran DPS sangat penting karena untuk memastikan ada tidak adanya kepatuhan syariah di BMT. Akan tetapi pada kenyataannya dalam operasional BMT masih dijumpai penyimpangan dari prinsip syariah dalam operasionalnya. Beberapa BMT ditengarai masih menggunakan sistem bunga walaupun istilah yang digunakan dalam akad-akadnya menggunakan bahasa arab. Banyak akad-akad yang terbukti begitu dekat dan hampir sama dengan akad dilembaga keuangan konvensional dan perbedaannya hanya dari segi istilah saja. Sebagai masyarakat menganggap, tidak ada bedanya antara BMT dengan lembaga keuangan konvensional karena dalam praktiknya sama saja. Sebagian mereka ada yang menolak untuk menggunakan jasa BMT karena belum sepenuhnya syariah.

Perkembangan BMT dari tahun-ketahun terus mengalami peningkatan yang pesat Pusat Inkubasi bisnis dan Usaha Kecil (PINBUK Departemen UMKM dan koperasi) memperkirakan

\footnotetext{
2 Agus Irianto, "Pengawasan BMT," 2017.

3 “UU No. 21 Tahun 2008 Tentang Perbankan Syariah Pasal 1 No. 12," n.d.
} 
jumlah BMT saat ini sekitar 5 ribu yang melayani nasabah sekitar 10 juta orang. Jumlah BMT di Propinsi Jawa Tengah menduduki urutan ketiga di Indonesia dengan jumlah BMT sebanyak 513. Dari 513 BMT yang ada di Jawa Tengah 18 BMT diantaranya berada di dari 18 BMT tersebut 3 BMT berada dikota Purwokerto, yaitu BMT Dana Mentari, BMT Khonsa, dan BMT NU Sejahtera.

Adapun permasalahan dalam penelitian ini adalah sebagai berikut: Bagaimana penerapan Syariah Compliance pada BMT yang ada di Kota Purwokerto, Bagaimana peran DPS yang mengawasi penerapan Syariah Compliance pada BMT yang ada di Kota Purwokerto, Apa saja kendala-kendala yang dihadapi oleh DPS dalam mengawasi penerapan Syariah compliance pada BMT yang ada di Kota Purwokerto.

\section{B. Metode Penelitian}

Penelitian ini menggunakan metode kualitatif dengan jenis penelitian field reseach (penelitian lapangan). Adapun lokasi yang menjadi tempat penelitian ini adalah BMT-BMT yang ada di Kota Purwokerto. Alasannya adalah karena BMT-BMT tersebut merupakan salah satu stakeholder dan user (pengguna lulusan) IAIN Purwokerto.

Sumber data yang digunakan adalah sumber data primer dan sekunder. Data perimer diperoleh dari pihak manajer dan anggota DPS pada BMT-BMT yang ada di Kota Purwokerto mengenai peran DPS dan penerapan shariah compliance. Untuk mendapatkan data tersebut menggunakan obsevasi dan wawancara dengan manajer dan anggota DPS. Adapun data sekunder tentang peran DPS dan penerapan shariah compliance dalam tataran teoritis dan empiris yang diperoleh dengan cara melakukan studi kepustakaan melalui penelahaan terhadap penelitian-penelitian terdahulu, buku-buku dan bahan-bahan lain yang berkaitan dengan tema tersebut.

Penulis menggunakan beberapa metode pengumpulan dalam penelitian ini yaitu observasi, wawancara dan dokumentasi. Dalam menganalisa datanya dimulai sejak sebelum memasuki lapangan penelitian, selama di lapangan dan setelah selesai dari lapangan. Analisa data sebelum ke lapangan dilakukan terhadap data-data dari hasil studi pendahuluan dan data sekunder yang digunakan untuk menentukan fokus penelitian. Pada saat penelitian, peneliti juga melakukan analisis terhadap jawaban responden. Apabila jawaban yang diwawancarai setelah dianalisis terasa belum memuaskan, maka penulis akan melanjutkan pernyataan lagi sampai tahap tertentu sehingga diperoleh data yang kredibel. Ada tiga tahap dalam analisis data kualitatif yaitu tahap reduksi data, display data, dan kesimpulan atau verifikasi .

\section{PEMBAHASAN}

\section{A. Penerapan Syari'ah Compliance pada BMT di Kota Purwokerto}

BMT adalah lembaga keuangan yang menjalankan kegiatan usahanya berdasarkan prinsip syariah. Prinsip syariah yang dimaksud adalah perjanjian antara BMT dengan nasabah berdasarkan fatwa yang dikeluarkan oleh DSN-MUI. BMT dalam operasionalnya harus bebas 
dari riba, gharar, maisir, menjalankan usaha yang halal, mengeluarkan zakat dan memberikan infaq dan shodaqoh untuk aktifitas sosial. ${ }^{4}$

Peran umum BMT yang dilakukan adalah melakukan pembinaan dan pendanaan yang berdasarkan sistem syariah. Peran ini menegaskan arti penting prinsip-prinsip syariah dalam kehidupan ekonomi masyarakat. Sebagai lembaga keuangan syariah yang bersentuhan dengan kehidupan masyarakat kecil yang serba cukup dari sisi materi dan ilmu pengetahuan, maka BMT mempunyai tugas penting dalam mengemban misi keislaman dalam aspek kehidupan masyarakat. $^{5}$

BMT terdiri dari dua istilah yaitu Baitul Mal dan Baitul Tamwil. Baitul Mal lebih mengarah pada usaha-usaha pengumpulan dan penyaluran dana non profit seperti zakat, infaq dan shodaqoh, Sedangkan Baitul Tamwil adalah sebagai usaha pengumpulan dan penyaluran dana profit. ${ }^{6}$

Perkembangan BMT terus mengalami pertumbuhan. Pusat Inkubasi Bisnis dan usaha kecil atau (PINBUK), Kementerian UMKM dan koperasi memperkirakan jumlah BMT ini sekitar 10 ribuan yang melayani nasabah sekitar 20 jutaan orang. Jumlah BMT di provinsi Jawa Tengah menduduki urutan ketiga di Indonesia dengan jumlah BMT sebanyak 513 lembaga dan serat 14 BMT berada di Kota Purwokerto yaitu BMT Amanah Wangon, BMT Al Amin, BMT Mentari Umat, BMT Dana Mentari Purwokerto, BMT Tijaroh Mentari Umat, BMT El Mentari PT Buana Mas, dan lain sebagainya. ${ }^{7}$ Namun pertumbuhan dan keberadaan BMT tersebut, berada di persimpangan jalan terutama setelah terbit UU No. 21 Tahun 2011 tentang Otoritas Jasa Keuangan (OJK). Sejatinya BMT sebagai lembaga intermediary dalam jasa keuangan, maka pengawasannya di bawah OJK. Namun lembaga pengawas BMT belum jelas. Dinas Koperasi tidak optimal dalam pengawasan demikian juga OJK. ${ }^{8}$

Syari'ah compliance adalah ketaatan lembaga keuangan syariah dalam memenuhi prinsip-prinsip syariah dalam operasionalnya. ${ }^{9}$ BMT merupakan lembaga keuangan yang beroperasi sesuai dengan prinsip-prinsip syariah. BMT dalam beroperasinya harus mengikuti ketentuan-ketentuan syariah khusunya menyangkut tata cara bermuamalat secara Islam. Prinsip tersebut harus diterapkan pada akad-akad yang digunakan dalam produk-produk BMT.

BMT dianggap telah memenuhi kepatuhan pada prinsip-prinsip syariah (syari'ah compliance) apabila dalam operasionalnya memenuhi kriteria-kriteria sebagai berikut: ${ }^{10}$

1. Tidak ada riba, gharar dan maisir dalam semua transaksinya.

2. Menjalankan bisnis yang berbasis pada keuntungan yang halal.

3. Menjalankan amanah yang dipercayakan nasabah kepada BMT.

4. Mengelola zakat, infaq shadaqah dengan amanah.

${ }^{4}$ M. Khaf, Ekonomi Islam (Yogyakarta: Pustaka Pelajar, 2007). 78.

${ }^{5}$ Yassine Essid, A Critique of The Origins of Islamic Economic Thought (Leiden: E.J Brill, 1995). 90.

${ }^{6}$ Heri Sudarsono, Bank Dan Lembaga Keuangan Syariah (Yogyakarta: Ekonisia, 2007). 96.

7 Koperasi dan UMKM, “Koperasi Dan UMKM Kab. Banyumas," 2015.

${ }^{8}$ Ahmad Erani Yustika, Ekonomi Kelembagaan: Definisi, Teori Dan Strategi (Jawa Timur: Bayu Media Publishing, 2016). 22.

9 Muhammad Abdul Manan, Islamic Economics: Teory and Practice (Pakistan: Shah Muhammad Ashraf Publishers, 1991). 79.

${ }^{10}$ Haider Naqvi, Ethics and Economics : An Islamic Synthesis (London: The Islamic Foundation, 1981). 56. 
INKLUSIF Vol 3. No. 2 Desember 2018

Berikut ini adalah hasil penelitian dari penerapan syariah compliance pada BMT yang ada pada Kota Purwokerto.

\section{Tidak Ada Riba dalam Transaksi BMT}

BMT dalam operasionalnya harus bebas dari riba. Pertanyaan yang berkaitan dengan unsur yang mengandung riba dalam operasional BMT adalah sebagai berikut :

a. Pengambilan keuntungan BMT dalam transaksi jual beli dan sewa didasarkan pada lama pembiayaan.

b. Pembagian bagi hasil dalam transaksi mudharabah dihitung dari hasil proyeksi pendapatan atau perkiraan.

c. BMT memberikan bagi hasil kepada nasabah sesuai nisbah dari pendapatan BMT.

Dari hasil penelitian tersebut menyatakan bahwa belum semua BMT di Kota Purwokerto bebas dari riba dalam transaksinya.

\section{Tidak Ada Unsur Gharar dalam Transaksi BMT}

BMT dalam operasionalnya harus bebas dari gharar. Pertanyaan yang dibuat berkaitan dengan unsur-unsur yang mengandung unsur gharar dalam operasional BMT adalah sebagai berikut :

a. Penentuan harga jual barang dalam murabahah mempertimbangkan nilai waktu dan uang.

b. Dalam transaksi mudharabah dan musyarakah tidak ada laporan pendapatan dari nasabah.

c. BMT menetapkan bagi hasil berdasarkan ekuivalensi tingkat suku bunga.

Dari hasil penelitian tersebut menyatakan bahwa semua BMT di Kota Purwokerto tidak mengandung gharar dalam transaksinya.

\section{Tidak Ada Maisir dalam Transaksi BMT}

BMT dalam operasionalnya harus bebas dari maisir. Pertanyaan yang berkaitan dengan unsur-unsur yang mengandung maisir dalam transaksi bank adalah sebagai berikut :

a. Dalam transaksi murabahah tidak ada kwitansi pembelian barang dari nasabah.

b. Dalam transaksi musyarakah perhitungan nisbahnya berdasarkan proyeksi pendapatan.

c. BMT memberikan hadiah kepada nasabah dan bagi hasil pendapatannya.

Dari hasil penelitian tersebut menyatakan bahwa belum semua BMT di Kota Purwokerto yang bebas dari maysir dalam transaksinya.

4. Menjalankan Usaha yang Halal

BMT yang menjalankan kegiatan usaha yang halal adalah apabila menyalurkan semua pembiayaannya pada jenis usaha yang benar-benar halal. Adapun dari hasil penelitian BMT di Kota Purwokerto telah mengeluarkan semua pembiayaan pada jenis usaha yang benarbenar halal.

\section{BMT Menjalankan Usahanya dengan Amanah}

BMT harus amanah dalam mengelola dana yang dipercayakan oleh nasabah. Pertanyaan yang berkaitan dengan unsur-unsur BMT menjalankan kegiatan usahanya dengan amanah sebagai berikut : 
a. Dalam transaksi murabahah BMT menjelaskan harga perolehan barang-barang keuntungan yang diinginkan.

b. Dalam transaksi musyarakah BMT meminta hasil sesuai proyeksi BMT.

c. BMT melaporkan laporan keuangannya pada nasabah.

Dari hasil penelitian tersebut menyatakan bahwa belum semua BMT di Kota Purwokerto amanah dalam menjalankan usahanya.

\section{B. Peran DPS dalam Mengawasi Penerapan Syari'ah Compliance}

Dewan pengawas Syariah (DPS) adalah dewan yang melakukan pengawasan terhadap prinsip syariah dalam kegiatan lembaga keuangan syariah yang menjalankan fungsinya bertindak secara independen. Dewan ini terdiri orang-orang yang memiliki kemampuan, baik di bidang hukum muamalah, hukum ekonomi dan perbankan serta kemampuan lain yang relevan dengan tugas keseharian. ${ }^{11}$ Artinya Dewan Pengawas Syariah adalah lembaga independen yang mempunyai spesialisasi keahlian dalam fiqih muamalah. Namun demikian, anggota Dewan Pengawas Syariah tidak hanya dituntut mempunyai spesialis dalam fiqih muamalah tetapi juga harus ahli dalam bidang lembaga keuangan Islam. Adapun Dewan Syariah Nasional (DSN), Majelis Ulama Indonesia (MUI) menerangkan bahwa DPS adalah badan yang ada di lembaga keuangan syariah (LKS) yang bertugas petugas mengawasi pelaksanaan keputusan DPS di lembaga keuangan syariah. ${ }^{12}$ Fungsi utama DPS adalah sebagai penasehat dan pemberi saran kepada Direksi Pimpinan Unit Usaha Syariah dan Pimpinan Kantor Cabang Syariah mengenai hal-hal yang terkait dengan aspek syariah. ${ }^{13}$

Dengan demikian DPS adalah satu badan independen di LKS yang perannya adalah mengawasi kegiatan usahanya sesuai dengan prinsip syariah. DPS wajib mengacu pada keputusan DSN dalam melaksanakan tugasnya. Sebagai pengawas Syariah fungsi DPS sangat strategis dan mulia, karena menyangkut kepentingan seluruh pengguna lembaga tersebut.

AAOIFI dalam Geovernance Standard for Islamic Finacial Institutions (GSIFI) menjelaskan bahwa peran DPS adalah $:^{14}$

"Directing, reviewing and supervising the activities of Islamic Financial Institution in order to ensure that they are in compliance with Islamic shari'a rules and principles."

Artinya: "mengarahkan, menilai, dan mengawasi seluruh aktivitas institusi keuangan Islam untuk memastikan aktivitasnya sesuai prinsip dan aturan syariah."

Selain tiga peran di atas, DSN-MUI menambahkan satu peran DPS yaitu melakukan sosialisasi dan edukasi kepada masyarakat tentang lembaga keuangan syariah melalui mediamedia yang sudah berjalan di masyarakat, seperti khutbah, majelis ta'lim, pengajianpengajian. Atau, lebih tepatnya peran DPS menurut DSN-MUI tersebut adalah sebagai pihak yang juga ikut memasarkan (marketing) lembaga keuangan syariah kepada masyarakat. ${ }^{15}$

\footnotetext{
${ }^{11}$ Yusuf S.M, Economic Justice in Islam (Lahore: Muhammad Asyraf, 1971). 61.

12 MUI, "Keputusan DSN MUI No. 01/2000 Tentang Pedoman Dasar DSN MUI," 2000.

${ }^{13}$ Muhammad Al Assal dan Fathi Abdul Karim, Hukum Ekonomi Islam (Jakarta: Pustaka Firdaus, 1999). 222.

${ }^{14}$ Ahmad Khurshid, Studies in Islamic Economics (Jeddah: King Abdul Aziz University, 1980). 90.

${ }^{15}$ Adiwarman Karim, Kajian Ekonomi Islam (Jakarta: TII, 2003). 23.
} 
Peran DPS pada BMT adalah mengarahkan operasional BMT agar sesuai dengan prinsip syariah, menilai dan mengawasi penerapan prinsip syariah serta turut dalam mensosialisasikan BMT. ${ }^{16}$ Penjabaran dari masing-masing tugas tersebut adalah sebagai berikut $:^{17}$

1. Directing yaitu memberikan pengarahan pemikiran saran dan nasehat kepada manajemen BMT mengenai hal-hal yang berkaitan dengan aspek Syariah.

2. Reviewing yaitu mencermati memeriksa dan melihat implementasi fatwa pada operasional BMT.

3. Supervising yaitu melaksanakan tugas pengawasan baik secara aktif maupun pasif pada implementasi fatwa DSN-MUI pada operasional BMT.

4. Mediating yaitu sebagai perantara antara BMT dengan DSN dalam mengkomunikasikan usul dan saran pengembangan produk dan jasa yang memerlukan kajian fatwa dari DSN.

5. Marketing yaitu melakukan sosialisasi dan edukasi kepada masyarakat tentang BMT melalui media-media yang sudah berjalan di masyarakat seperti khutbah, majelis taklim dan pengajian pengajian.

6. Supporting yaitu memberikan dukungan baik networking pemikiran, motivasi dan doa untuk mengembangkan BMT dan ekonomi syariah.

7. DPS menjadi nasabah penyimpan atau penyalur dana di BMT dan lembaga keuangan syariah lainnya.

Adapun hasil penelitian tentang peran DPS dalam mengawasi syari'ah complaince pada BMT-BMT di Kota Purwokerto adalah sebagai berikut:

1. DPS memberikan pengarahan, pemikiran, saran dan nasehat kepada manajemen BMT mengenai hal-hal yang berkaitan dengan aspek Syariah

Dari lima DPS yang menjawab pertanyaan, semuanya menjawab YA, pada peran nomor yang pertama ini. Ini menunjukan bahwa semua DPS pada BMT-BMT di Kota Purwokerto telah memberikan pemikiran, saran dan nasehat kepada manajemen BMT mengenai halhal yang berkaitan dengan aspek syariah.

2. DPS mencermati, memeriksa, mengkaji dan meneliti implementasi fatwa DSN pada operasional BMT

Semua DPS menjawab YA, pada peran yang kedua ini. Ini menunjukkan bahwa semua DPS pada BMT-BMT di Purwokerto telah mencermati, memeriksa mengkaji dan menilai implementasi fatwa DSN pada operasional BMT.

3. DPS mengawasi implementasi fatwa DSN pada operasional BMT

Empat dari lima DPS menjawab YA pada peran yang ketiga ini, sedangkan satu DPS yang lain menjawab TIDAK. Ini artinya bahwa belum semua DPS pada BMT-BMT di Purwokerto mengawasi implementasi fatwa DSN pada operasional BMT.

\footnotetext{
${ }^{16}$ Ahmad Mustaq, Business Ethic in Islam (Pakistan: international Institute of Islamic Thought, 2001). 49.

17 Munawar Iqbal dan Ausaf Ahmad, Islamic Finance and Economic Development (New York: Palgrave MacMillan, 2015). 99.
} 


\section{DPS melakukan sosialisasi dan edukasi tentang BMT kepada masyarakat}

Dari lima DPS yang mengembalikan kuesioner, tiga diantaranya menjawabnya YA pada peran yang keempat ini, sedangkan 2 DPS yang lain menjawab TIDAK. Ini menunjukkan bahwa DPS pada BMT-BMT di Purwokerto belum semuanya melakukan sosialisasi dan edukasi tentang BMT kepada masyarakat.

5. DPS menjadi perantara antara BMT dengan DSN dalam mengkomunikasikan usul dan saran pengembangan produk baru BMT yang memerlukan kajian dan fatwa DSN

Tiga DPS menjawab YA, sementara dua DPS yang lainnya menjawab TIDAK. Ini menunjukkan bahwa DPS pada BMT-BMT yang ada di Kota Purwokerto belum semuanya yang berperan sebagai perantara antara BMT dan DSN dalam mengkomunikasikan usul dan saran pengembangan produk baru BMT yang memerlukan kajian dan fatwa DSN.

6. DPS memberikan dukungan baik networking, pemikiran, motivasi dan doa untuk pengembangan BMT dan ekonomi syariah

Semua DPS menjawab YA pada peran yang keenam ini. Ini menunjukkan bahwa DPS pada BMT-BMT yang ada di Purwokerto telah memberikan dukungan baik networking, pemikiran motivasi dan doa untuk pengembangan BMT dan ekonomi syariah.

\section{DPS menjadi nasabah penyimpan atau penyaluran di BMT}

Semua DPS menjawab YA, pada peran yang ketujuh ini. Ini menunjukkan bahwa DPS pada BMT-BMT yang ada di Purwokerto telah menjadi nasabah penyimpan atau penyalur di BMT.

Dari pemaparan diatas mengenai jawaban-jawaban yang diberikan oleh masingmasing DPS menunjukan bahwa belum semua DPS pada BMT-BMT di Purwokerto menjalankan ketujuh perannya. Mereka baru menjalankan empat perannya yang meliputi directing, revewing, supervising, dan playing. Sedangkan, tiga peran lain yang meliputi supervising, marketing dan mediating belum dilaksanakan oleh DPS pada BMT-BMT yang ada di Purwokerto. Jadi dapat disimpulkan bahwa peran DPS dalam mengawasi penerapan syariah compliance pada BMT-BMT yang ada di Kota Purwokerto masih belum maksimal.

\section{Kendala-kendala yang Dihadapi oleh DPS dalam Mengawasi Penerapan Syari'ah Compliance}

Namun, demikian dalam menjalankan tugas dan tanggung jawabnya, DPS menghadapi beberapa kendala seperti yang dihadapi oleh DPS-DPS yang ada di BMT-BMT yang ada di Kota Purwokerto. Kendala-kendala tersebut dapat diklasifikasi sebagai berikut :

\section{Keterbatasan Pengetahuan DPS tentang Operasional BMT}

Untuk melaksanakan tugas pengawasan, anggota DPS harus memenuhi klasifikasi sebagai DPS agar fungsi-fungsi pengawasannya dapat berjalan optimal. Syarat utama yang harus dimiliki oleh anggota DPS adalah penguasaan fiqih muamalah terapan dan penguasaan ilmu ekonomi dan keuangan. Dengan demikian dua disiplin tersebut harus dimiliki oleh anggota DPS.

Untuk memahami kualifikasi diatas, di masa lalu pihak perbankan syariah dan Bank Indonesia mengalami kesulitan, karena langkanya ulama ahli fiqih muamalah yang 
memahami Ilmu Ekonomi, keuangan khususnya perbankan. Namun pada saat ini juga mudah untuk mencari Ulama yang ahli fiqih muamalah, tetapi tidak menguasai Ilmu Ekonomi, keuangan dan perbankan. DPS seharusnya memahami secara mendalam tentang mekanisme operasional bank syariah, memahami keunggulan-keunggulan bank syariah, memahami perbedaan bank syariah dan bank konvensional, produk-produk bank syariah, perbedaan bunga dengan margin murabahah, bunga dengan bagi hasil dan mampu membaca dan memahami laporan keuangan.

Akhirnya, perbankan syariah mengangkat DPS karena kharisma dan kepopulerannya di tengah masyarakat, bukan karena keilmuannya di bidang ekonomi dan perbankan syariah serta ilmu fiqih muamalah. Sehingga, figure DPS terkesan hanya sebagai pajangan yang kurang berfungsi dalam menjalankan pengawasan. Akibatnya fungsi mereka sebagai DPS tidak berjalan optimal.

Dengan kondisi-kondisi seperti diatas kemudian menyebabkan pengawasan yang dilakukan oleh DPS belum maksimal. Keadaan seperti ini hampir diakui oleh seluruh DPS pada BMT yang ada di Kota Purwokerto dalam mangawasi kepatuhan pada prinsip syariah.

\section{Kesibukan DPS di Tempat Asalnya}

Orang yang diangkat sebagai DPS pada BMT yang ada di Kota Purwokerto sudah mempunyai kesibukan tertentu di tempat lain, seperti dosen, Ulama, guru, da'i dan pengelola pondok pesantren, karena kesibukan-kesibukan tersebut menyebabkan pengawasan yang dilakukan menjadi tidak optimal. Terkadang ada DPS yang mengunjungi BMT hanya sekali dalam sebulan, ada juga yang hanya bisa dihubungi via telepon. Karena kesibukan mereka di luar sana, fungsi-fungsi yang harusnya dijalankan tidak bisa dilaksanakan.

Hampir seluruh DPS pada BMT yang ada di Kota Purwokerto sudah mempunyai pekerjaan tetap di tempatnya masing-masing sebelum menjadi DPS. Misalnya, Anggota DPS pada BMT Mentari adalah guru PNS, sedangkan lainnya pengusaha dan wiraswasta.

\section{PENUTUP}

BMT yang ada di Kota Purwokerto belum sepenuhnya menerapkan syari'ah compliance. Dari enam unsur yang terdapat dalam Syariah Compliance, dari hasil penelitian ternyata BMT baru menerapakan dua unsur, yaitu menjalankan kegiatan usaha pada keuntungan yang halal dan amanah dalam membayar dan mengelola zakat, infaq dan shodaqoh. Sedangkan 3 unsur yang lain belum semuanya diterapkan dalam menjalankan operasionalnya, adapun empat unsur tersebut adalah bebas riba, gharar, maisir.

Peran DPS pada BMT yang ada di Kota Purwokerto belum semuanya melakukan pengawasan dalam penerapatan syari'ah compliance. Adapun BMT baru mejalankan empat perannya yang meliputi : directing, reviewing, supporting dan playing, sedangkan tiga peran lain yang meliputi: supporting, marketing dan mediating belum semuanya dilaksanakan oleh DPS pada BMT yang ada di Kota Purwokerto. 
INKLUSIF Vol 3. No. 2 Desember 2018

Adapun kendala-kendala yang dihadapi DPS dalam menjalankan perannya sebagai pengawas syari'ah compliance pada BMT di Kota Purwokerto yaitu keterbatasan pengetahuan DPS tentang operasional perbankan dan kesibukan DPS di tempat tugas asalnya.

\section{DAFTAR PUSTAKA}

Ahmad, Munawar Iqbal dan Ausaf. Islamic Finance and Economic Development. New York: Palgrave MacMillan, 2015.

Essid, Yassine. A Critique of The Origins of Islamic Economic Thought. Leiden: E.J Brill, 1995. Irianto, Agus. "Pengawasan BMT," 2017.

Karim, Adiwarman. Kajian Ekonomi Islam. Jakarta: TII, 2003.

Karim, Muhammad Al Assal dan Fathi Abdul. Hukum Ekonomi Islam. Jakarta: Pustaka Firdaus, 1999.

Khaf, M. Ekonomi Islam. Yogyakarta: Pustaka Pelajar, 2007.

Khurshid, Ahmad. Studies in Islamic Economics. Jeddah: King Abdul Aziz University, 1980.

Koperasi dan UMKM. "Koperasi Dan UMKM Kab. Banyumas," 2015.

Manan, Muhammad Abdul. Islamic Economics: Teory and Practice. Pakistan: Shah Muhammad Ashraf Publishers, 1991.

MUI. “Keputusan DSN MUI No. 01/2000 Tentang Pedoman Dasar DSN MUI," 2000.

Mustaq, Ahmad. Business Ethic in Islam. Pakistan: international Institute of Islamic Thought, 2001. Naqvi, Haider. Ethics and Economics : An Islamic Synthesis. London: The Islamic Foundation, 1981. S.M, Yusuf. Economic Justice in Islam. Lahore: Muhammad Asyraf, 1971.

Sudarsono, Heri. Bank Dan Lembaga Keuangan Syariah. Yogyakarta: Ekonisia, 2007.

"UU No. 21 Tahun 2008 Tentang Perbankan Syariah Pasal 1 No. 12," n.d.

Yustika, Ahmad Erani. Ekonomi Kelembagaan: Definisi, Teori Dan Strategi. Jawa Timur: Bayu Media Publishing, 2016. 